\title{
Correlation of FOXC1 protein with clinicopathological features in serous ovarian tumors
}

\author{
LU-YING WANG ${ }^{1}$, LAN-SHUANG LI ${ }^{1}$ and ZHU YANG $^{2}$ \\ ${ }^{1}$ Department of Gynecology and Obstetrics, Chengdu Women and Children's Hospital, Chengdu, Sichuan 610091; \\ ${ }^{2}$ Department of Gynecology and Obstetrics, Second Affiliated Hospital of Chongqing Medical University, \\ Chongqing 400010, P.R. China
}

Received October 24, 2014; Accepted August 20, 2015

DOI: $10.3892 / \mathrm{ol} .2015 .3996$

\begin{abstract}
Transcriptional factor FOXC1 has been demonstrated to play a key role in embryogenesis in animal studies and may participate in tumorigenesis. However, the specific function of this gene in ovarian tumors has not been fully determined. In this study, potential correlations between FOXC1 expression and clinicopathological features of serous ovarian tumors were investigated. FOXC1 expression was analyzed in SKOV-3 and HO-8910 cell lines and serous ovarian tumor tissues. A significant correlation was observed between FOXC1 protein expression and pathological subtype as well as FIGO stage $(\mathrm{P}<0.05)$ in serous ovarian tumors in our retrospective study. No significant association was revealed between FOXC1 protein expression and the clinicopathological factors of age, histological grade and volume of ascites $(\mathrm{P}>0.05)$. The results suggest that high expression of $\mathrm{FOXC1}$ protein may serve as a marker for benign serous ovarian tumors and a suggest a trend towards good prognosis.
\end{abstract}

\section{Introduction}

Ovarian carcinoma is one of the most common types of cancer and is among the leading causes of mortality from gynecological malignancies in the world (1). It is the fifth leading cause of cancer-related mortality among females in Western countries (2). No nationwide statistical data on ovarian cancer have been reported in China as yet. It was estimated that there were 19,300 new cases of ovarian cancers per year in China during

Correspondence to: Dr Lu-Ying Wang, Department of Gynecology and Obstetrics, Chengdu Women and Children's Hospital, 1617 Riyue Avenue, Chengdu, Sichuan 610091, P.R. China

E-mail: pumpum215@hotmail.com

Dr Zhu Yang, Department of Gynecology and Obstetrics, Second Affiliated Hospital of Chongqing Medical University, 76 Linjiang Road, Chongqing 400010, P.R. China

E-mail: cqyangz@vip.163.com

Key words: transcriptional factor FOXC1, clinicopathological features, serous ovarian tumors the 1980s, and an upward trend in incidence has been observed in recent years (3). However, the molecular determinants of ovarian tumorigenesis are still under investigation, while it is conceivable that ovarian cancer, like most other cancers, arises as a result of acquired alterations in gene expression due to specific signal transduction pathways (4).

The transcriptional factor FOXC1, also known as FREAC3 and FKHL7 $(5,6)$, is a member of the forkhead box (FOX)/winged-helix transcription factor family, which consists of almost 100 members, with orthologs expressed in an array of species ranging from yeast to humans (7). These transcriptional factors share a highly conserved DNA-binding forkhead domain (FHD) of 110 amino acids, consisting of three $\alpha$-helices and two large loops that form 'wing' structures. It is through the FHD that FOX proteins are able to interact with DNA. The function of FOX genes has become better understood in recent years. FOX is a group of critical transcription factors which control a variety of processes, including regulation of embryogenesis and maintenance of differentiated cell states, major organ systems and tissues from all three germ layers in the brain, cardiovascular system, lung and kidney (8-11). Mutation studies in mice, zebrafish and Drosophila have revealed a diverse range of key roles of these genes during embryonic development, including node formation and anterior-posterior and left-right axis patterning (12-14). In addition to their vital roles in normal development processes, a number of FOX genes also participate in tumorigenesis (12).

The FOXC1 transcript has been detected in multiple human organs using northern blot analysis $(5,6,15)$. It is located on human chromosome 6p25 (6), encoding a 553 amino acid protein $(16,17)$. The FOXC1 coding sequence contains no introns and comprises a 1659-bp open reading frame that contains the FHD. The molecular weight of the FOXC1 protein is $56,789 \mathrm{Da}$.

Studies of animal models have demonstrated the significance of FOXC1 as a key transcription factor in development. Recombinant FOXC1 null mice die peri- or postnatally with massive skeletal, cardiac, ocular and urogenital anomalies (18-20). Mutations of the FOXC1 gene in humans result in various glaucoma-related phenotypes, including Axenfeld-Rieger anomaly and cardiac valve abnormalities $(5,6,21,22)$. A previous study also revealed that FOXC1 might be involved in several types of genital tumorigenesis, including human 
prostate, endometrial and ovarian cancers $(23,24)$. The FOXC1 gene may exert a negative regulation of cell proliferation in several gynecological cancer cell lines (24).

However, it is unclear whether the FOXC1 protein exists in ovarian tumor cell lines and tissues. In addition, the clinical significance and molecular mechanism of the FOXC1 protein in ovarian carcinoma remain poorly understood. This study was designed to clarify the issue and explore the association of FOXC1 protein expression with clinicopathological factors and outcome of the disease.

\section{Materials and methods}

Cell culture. Two human serous ovarian cystadenocarcinoma cell lines were used in the present study: SKOV-3 was a gift from the Ultrasound Institute of Chongqing Medical University, China, and HO-8910 was purchased from Nanjing KeyGen Biotechnology Company, China. SKOV-3 and HO-8910 cells were maintained in RPMI-1640 medium (Gibco-Invitrogen, Carlsbad, CA, USA) supplemented with $10 \%$ fetal calf serum (Gibco-Invitrogen) and $1 \%$ penicillin/streptomycin at $37^{\circ} \mathrm{C}$ in the presence of $5 \% \mathrm{CO}_{2}$.

Tissue specimens. Twenty-five samples of serous ovarian cystoadenoma, 15 samples of ovarian borderline serous cystoadenoma and 40 samples of serous ovarian cystadenocarcinoma, all paraffin-embedded, were retrieved from case files at the Department of Pathology of the Second Affiliated Hospital of Chongqing Medical University, China, between February 2004 and February 2009. The diagnosis of serous ovarian tumors was based on typical light microscopic findings. The study was approved by the ethics committee of the Second Affiliated Hospital of Chongqing Medical University.

Reverse transcription-quantitative polymerase chain reaction $R T$ - $q P C R)$. Total RNA was isolated from cultured SKOV-3 and HO-8910 cells with TRIzol reagent (Takara Bio Inc., Otsu, Japan). Total RNA (500 ng) was used as a template for RT using an RNA RT kit from Takara Bio Inc. The RT reaction was set up in a $10 \mu \mathrm{l}$ mixture containing $2 \mu \mathrm{l} 5 \mathrm{X}$ PrimeScript buffer (for qPCR), $0.5 \mu \mathrm{l}$ PrimeScript RT enzyme mix, $0.5 \mu \mathrm{l}$ random 6 mers $(100 \mu \mathrm{M})$ and $0.5 \mu \mathrm{l}$ oligo-dT primer $(50 \mu \mathrm{M})$. Incubation was performed in an ABI 9700 DNA thermal cycler (Applied Biosystems, Foster City, CA, USA) for $15 \mathrm{~min}$ at $37^{\circ} \mathrm{C}$, followed by $5 \mathrm{sec}$ at $85^{\circ} \mathrm{C}$. qPCR was performed on an ABI 7300 real-time fluorescence quantitative PCR thermocycler (Applied Biosystems) using an SYBR PrimeScript real-time PCR kit (Takara Bio Inc.). Thermal cycler conditions involved holds for $10 \mathrm{sec}$ at $94^{\circ} \mathrm{C}$, followed by 40 cycles of $5 \mathrm{sec}$ at $94^{\circ} \mathrm{C}$ and $30 \mathrm{sec}$ at $60^{\circ} \mathrm{C}$. The relative amount of mRNA was calculated using the comparative threshold cycle method. The housekeeping gene $\beta$-actin served as an internal parameter. The amplification efficiencies of the target and reference were demonstrated to be approximately equal with a slope of log input amount to threshold cycle $<0.1$. The following oligonucleotide primers were used: FOXC1 forward 5'-AGCATCCGCCACAACCTC-3', reverse 5'-GCCTGTCCT TCTCCTCCTT-3'; and $\beta$-actin forward 5'-TGGCACCCA GCACAATGAA-3', reverse 5'-CTAAGTCATAGTCCGCCT AGAAGCA-3'. Primers were designed using Primer3 software, available from the Primer3 v. 0.4.0 website (http://frodo.wi.mit.edu/primer3/, Whitehead Institute for Biomedical Research, Cambridge, MA, USA).

Western blot analysis. SKOV-3 and HO-8910 cells in the exponential phase of growth were pooled and centrifuged at $250 \times \mathrm{g}$ at $4^{\circ} \mathrm{C}$ for $10 \mathrm{~min}$, and the packed cell volume was estimated. The deposition was incubated on ice for $30 \mathrm{~min}$ in $200 \mu \mathrm{l}$ lysis buffer A $(10 \mathrm{mmol} / \mathrm{l} \mathrm{HEPES}, \mathrm{pH}=7.9,10 \mathrm{mmol} / \mathrm{l}$ $\mathrm{KCl}, 1.5 \mathrm{mmol} / 1 \mathrm{MgCl}_{2}, 0.1 \mathrm{mmol} / \mathrm{l}$ ethylenedinitrolotetraacetic acid, $0.05 \%$ Nonidet P-40, $1 \mathrm{mmol} / \mathrm{l}$ dithiothreitol, $1 \mathrm{mmol} / 1$ phenylmethyl sulfonyl fluoride, $1 \mathrm{mg} / 1$ leupeptin), and centrifuged at $250 \mathrm{x} \mathrm{g}$ at $4^{\circ} \mathrm{C}$ for $10 \mathrm{~min}$. The supernatant from this spin was used as the cytoplastic extract. The precipitum was then incubated on ice for $30 \mathrm{~min}$ in $100 \mu \mathrm{l}$ lysis buffer B (20 mmol/1 HEPES, pH=7.9, $420 \mathrm{mmol} / \mathrm{l} \mathrm{NaCl}$, $1.5 \mathrm{mmol} / 1 \mathrm{MgCl}_{2}, 0.2 \mathrm{mmol} / 1$ ethylenedinitrolotetraacetic acid, $1 \mathrm{mmol} / 1$ dithiothreitol and phenylmethyl sulfonylfluoride, $1 \mu \mathrm{g} / \mathrm{ml}$ leupeptin) before centrifuge at $14,000 \mathrm{x} \mathrm{g}$ at $4^{\circ} \mathrm{C}$ for $15 \mathrm{~min}$. The supernatant was the nuclear extract. Identical amounts of protein from the extract were denatured and then subjected to electrophoresis on a 5\% stacking and $12 \%$ separating sodium dodecyl sulfate (SDS) polyacrylamide gel using a Mini PROTEAN apparatus (Bio-Rad Laboratories, Inc., Hercules, CA, USA). Electrophoretic transfer to nitrocellulose was accomplished at $80 \mathrm{~V}$ for $2 \mathrm{~h}$ in $25 \mathrm{mmol} / 1$ Tris,

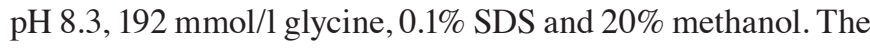
membrane was then blocked with $5 \%$ skimmed milk overnight at $4{ }^{\circ} \mathrm{C}$, followed by two 5 -min washes in phosphate-buffered saline/1\% Tween-20 (PBST). The membrane was incubated with primary FOXC1 antibody (goat anti-human polyclonal antibody, sc-21396, Santa Cruz Biotechnology Inc., Santa Cruz, CA, USA; dilution 1:200) at room temperature for $2 \mathrm{~h}$ in antibody dilution buffer (1\% bovine serum albumin in PBST) followed by three 5-min washes in PBST. Secondary antibody (donkey anti-goat antibody, Santa Cruz Biotechnology, Inc.; dilution 1:5,000) was diluted in antibody dilution buffer, and then added to the membrane for $2 \mathrm{~h}$ at room temperature, followed by three 5-min washes in PBST. Finally, detection procedures were performed using an enhanced chemiluminescence western blotting detection kit (Beyotime Institute of Biotechnology, Inc.).

Immunohistochemistry. The tissue samples were fixed by immersion in $10 \%$ buffered formalin and subsequently embedded in paraffin according to standard protocols. Sections for immunohistochemistry were cut at $5 \mu \mathrm{m}$, mounted on Superfrost Plus glass slides (Thermo Fisher Scientific, Inc., Waltham, MA, USA ), baked for $30 \mathrm{~min}$ at $70^{\circ} \mathrm{C}$ and left to dry overnight at $37^{\circ} \mathrm{C}$. Subsequently, the sections were deparaffinized and rehydrated by passing through xylene and a graded series of ethanol solutions. Before the primary antibody was applied, antigen retrieval was performed by boiling the sections in $10 \mathrm{mmol} / \mathrm{l}$ sodium citrate buffer $(\mathrm{pH} 6.0)$ at $98^{\circ} \mathrm{C}$ in a microwave oven at $750 \mathrm{~W}$ for a total of $30 \mathrm{~min}$ (three cycles of $10 \mathrm{~min}$ each). Slides were left to cool down to room temperature in the antigen retrieval solution for $30 \mathrm{~min}$. To block endogenous peroxidase activity, the sections were incubated with $3 \%$ hydrogen peroxide in methanol for $10 \mathrm{~min}$. After blocking for $10 \mathrm{~min}$ in rabbit serum, the sections were 
Table I. Correlation of FOXC1 protein with clinicopathological features in serous ovarian tumors.

\begin{tabular}{|c|c|c|c|c|}
\hline \multirow[b]{2}{*}{ Variables } & \multirow[b]{2}{*}{ No. of cases } & \multicolumn{2}{|c|}{$\begin{array}{l}\text { Immunohistochemical } \\
\text { results }[\mathrm{n}(\%)]\end{array}$} & \multirow[b]{2}{*}{ P-value } \\
\hline & & $(+)$ & $(-)$ & \\
\hline Age group ${ }^{a}$ & & & & 0.1500 \\
\hline$<48$ & 38 & $25(65.8)$ & $13(34.2)$ & \\
\hline$\geq 48$ & 40 & $20(50.0)$ & $20(50.0)$ & \\
\hline Pathological subtype & & & & $<0.0010$ \\
\hline Benign & 25 & $21(84.0)$ & $4(16.0)$ & \\
\hline Borderline & 15 & $10(66.7)$ & $5(33.3)$ & \\
\hline Malignant & 40 & $15(37.5)$ & $25(62.5)$ & \\
\hline Histological grade of cystadenocarcinoma & & & & 0.1600 \\
\hline Well-differentiated & 7 & $4(57.1)$ & $3(42.9)$ & \\
\hline Moderately differentiated & 21 & $9(42.9)$ & $12(57.1)$ & \\
\hline Poorly differentiated & 12 & $2(16.7)$ & $10(83.3)$ & \\
\hline FIGO stages of cystadenocarcinoma & & & & 0.0035 \\
\hline I-II & 12 & $9(75.0)$ & $3(25.0)$ & \\
\hline III-IV & 28 & $6(21.4)$ & $22(78.6)$ & \\
\hline Volume of cystadenocarcinoma ascites & & & & 0.1900 \\
\hline None & 7 & $4(57.1)$ & $3(42.9)$ & \\
\hline Small amount & 12 & $6(50.0)$ & $6(50.0)$ & \\
\hline Moderate amount & 8 & $3(37.5)$ & $5(62.5)$ & \\
\hline Large amount & 13 & $2(15.4)$ & $11(84.6)$ & \\
\hline
\end{tabular}

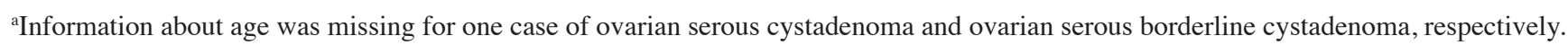

incubated with a specific primary antibody that recognized FOXC1 (goat polyclonal antibody, sc-21396, Santa Cruz Biotechnology Inc.; dilution 1:200) at $4^{\circ} \mathrm{C}$ overnight. Then, the standard streptavidin-biotin complex immunoperoxidase technique (goat streptavidin-peroxidase kit, Maixin Biotechnology Co., Fuzhou, China) was used according to the manufacturer's instructions. All the sections were counterstained with hematoxylin. Known positive internal controls (normal endometrium tissues) (24) and negative controls (sections in which the primary antibody was substituted with PBS) were also stained in each run. Staining was assessed without any knowledge of the clinical data by two observers.

SKOV-3 cells and HO-8910 cells were harvested in the exponential phase of growth and were seeded into six-well plates containing sterile coverslips at a concentration of $1 \times 10^{6}$ cells per well. After $48 \mathrm{~h}$, cells were washed with PBS and fixed with $4 \%$ paraformaldehyde at room temperature for $30 \mathrm{~min}$. After rinsing in washing buffer, the cells were incubated with $3 \%$ hydrogen peroxide in methanol for $10 \mathrm{~min}$ and permeabilized using $0.05 \%$ Triton $\mathrm{X}-100 / \mathrm{PBS}$ for $10 \mathrm{~min}$. The following steps were performed in the same way as for immunohistochemistry of tumor tissue.

Statistical analysis. The correlations between FOXCI expression and clinicopathological parameters were examined by the Chi-square test or Fisher's exact test. Statistical calculations were performed using SAS software for Windows (Microsoft,
Redmond, WA, USA). P $\leq 0.05$ was considered to indicate a statistically significant difference.

\section{Results}

Identification of FOXCl expression in serous ovarian carcinoma cell lines. To study FOXC1 gene expression in ovarian tumors, serous ovarian carcinoma cell lines HO-8910 and SKOV-3 were selected. RT-qPCR was employed to evaluate FOXC1 mRNA expression in the two cell lines. Western blot analysis and immunohistochemistry with the anti-FOXC1 antibody were performed to confirm FOXC1 protein expression. There was no significant difference in FOXC1 mRNA and protein levels between the two cell lines (Fig. 1A-C). A single immunoreactive band of $56 \mathrm{kDa}$ was detected, corresponding to the molecular weight predicted for FOXC1, and no non-specific bands were detected with this antibody. However, FOXC1 immunohistochemistry assay revealed dichotomous immunoreactivity in the nucleus and cytoplasm of the two cell lines. FOXC1 was localized mainly in the nucleus of SKOV-3 and HO-8910 cells, while less staining was observed in the cytoplasm, which was in accordance with the results of western blot analysis.

FOXC1 protein expression in serous ovarian tumors and its clinicopathological significance. Staining patterns on immunohistochemistry were consistent within each tissue. 
A

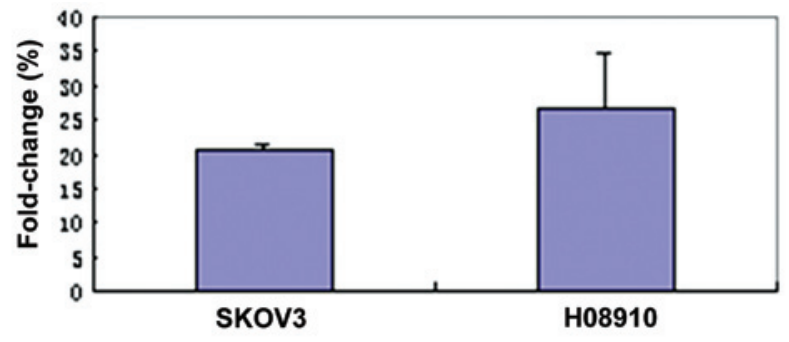

B

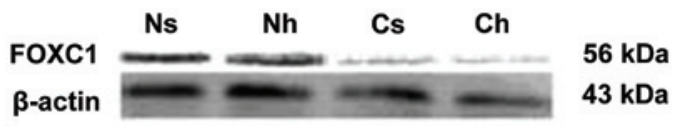

C
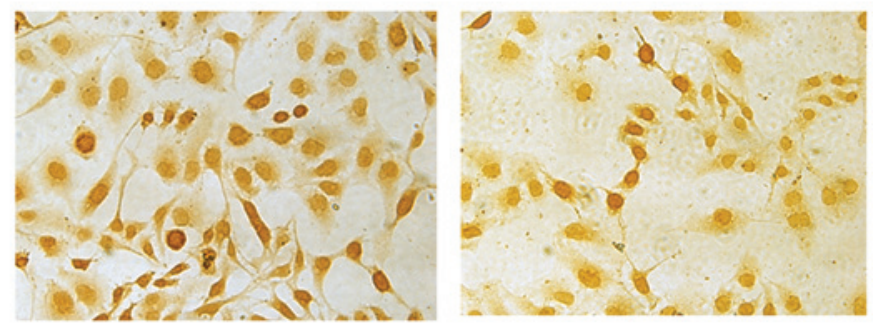

Figure 1. FOXC1 expression in serous ovarian carcinoma cell lines. (A) FOXC1 mRNA levels in SKOV-3 and HO-8910 cell lines. (B) FOXC1 protein levels in SKOV-3 and HO-8910 cell lines. Ns and Nh represent nuclear protein of SKOV-3 and HO-8910 cells, respectively; Cs and Ch represent cytoplasmic protein of SKOV-3 and HO-8910 cells, respectively. $\beta$-actin was used as an internal control in western blot analysis. (C) Left panel: Nuclear and cytoplasmic immunostaining of FOXC1 was observed in SKOV-3 cells, although staining was less intense in the cytoplasm than in the nucleus, which was in accordance with the results of western blot analysis. Right panel: Nuclear and cytoplasmic staining of FOXC1 was observed in HO-8910 cells, although staining was less intense in the cytoplasm than in the nucleus, which was in accordance with the results of western blot analysis.

A

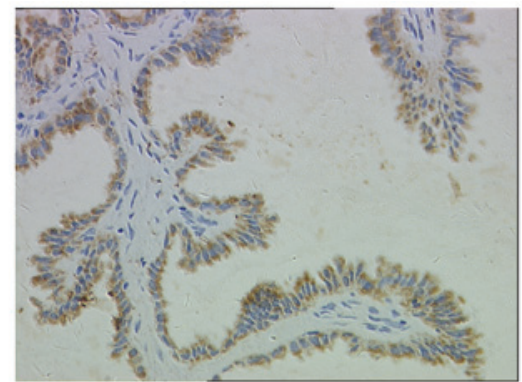

C

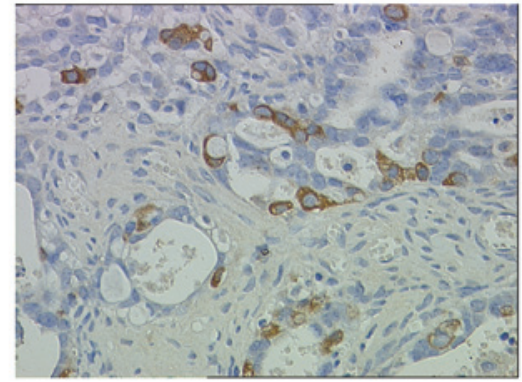

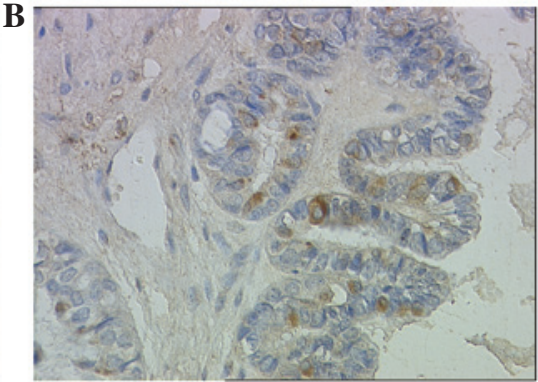

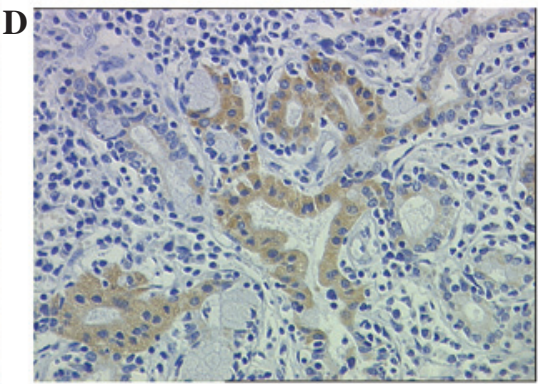

Figure 2. Cytoplasmic FOXC1 immunoreactivity in serous ovarian tumors and normal endometrium tissue (magnification, x400). (A) The majority of neoplastic cells are positive. Positive immunostaining of FOXC1 was observed exclusively in the cytoplasm of glandular epithelium cells in serous cystadenoma; no nuclear positivity was observed; (B) Positive immunostaining of FOXC1 was observed exclusively in the cytoplasm of glandular epithelium cells in serous borderline cystadenoma; (C) Positive immunostaining of FOXC1 was observed exclusively in the cytoplasm of glandular epithelium cells in well-differentiated serous cystadenocarcinoma. (D) FOXC1 immunostaining in normal endometrium tissue was used as a positive control. Positivity was observed exclusively in the cytoplasm of endometrial glandular cells.

A sample was considered to demonstrate positive immunoreactivity if $>30 \%$ of the cells exhibited intracellular staining following standard immunostaining. Intercellular structure and inflammatory cells did not express FOXC1 (Fig. 2A-D). In contrast with the observation in cell lines (Fig. 1C), no nuclear FOXC1 immunoreactivity was detected in any of serous 
ovarian tumor tissues. Notably, positive immunostaining for FOXC1 was observed exclusively in the cytoplasm in 46 $(57.5 \%)$ cases of serous ovarian tumors.

Correlations between the incidence of cytoplasmic FOXC1 immunoreactivity and clinicopathological features of serous ovarian tumors are shown in Table I. A retrospective investigation was conducted to clarify the correlations of FOXC1 protein with clinicopathological variables of serous ovarian tumors. A total of 80 patients with a medium ( \pm standard deviation) age of 48 years (range, 25 to 74 years) were included in this study. According to the World Health Organization (1999) criteria, the 80 serous ovarian tumors were classified histologically as benign (serous ovarian cystoadenoma), borderline (ovarian borderline serous cystoadenoma or low malignant potential tumor) or malignant (serous ovarian cystadenocarcinoma) (25). Serous ovarian cystadenocarcinomas were graded as well, moderately or poorly differentiated. Patients were assigned a clinical stage in accordance with the International Federation of Gynecology and Obstetrics (FIGO) 2000 standards (26). Among the 80 cases of serous ovarian tumor, 25 were benign, 15 borderline and 40 malignant. Among the 40 cases of serous ovarian cystadenocarcinoma, 7 were well differentiated, 21 moderately differentiated and 12 poorly differentiated. Twelve cases were in stage I-II and 28 were in stage III-IV. The volume of ascites in cystadenocarcinoma was defined as small $(\leq 500 \mathrm{ml})$, medium $(500-2,000 \mathrm{ml})$ or large $(>2,000 \mathrm{ml})$. There were 7 cases with no ascites, 12 with a small amount, 8 with a medium amount and 13 with a large amount. None of the serous ovarian cystadenocarcinoma patients had received preoperative chemotherapy or radiotherapy. FOXC1 positive reactivity was observed in 21 (84\%) cases of serous ovarian cystoadenoma, $10(66.7 \%)$ serous ovarian borderline cystoadenomas and $15(37.5 \%)$ serous ovarian cystadenocarcinomas. In malignant tumors, FOXC1-positive immunohistochemistry was observed in 4 well-differentiated cases $(57.1 \%), 9$ moderately-differentiated cases $(42.9 \%)$ and 2 poorly-differentiated cases $(16.7 \%)$ based on the histological criteria used. According to the FIGO criteria, 9 cases were in stage I and II (75\%) and 6 were in stage III and IV (25\%). Four cases were observed with no ascites (57.1\%), 6 with a small amount (50\%), 3 with a medium amount (37.5\%) and 2 with a large amount (15.4\%). A significant correlation between positive FOXC1 immunoreactivity and pathological subtypes of serous ovarian tumor was identified, and FOXC1 protein significantly decreased with advancing FIGO stage $(\mathrm{P}<0.01)$. No significant association was revealed between FOXC1 protein expression and the clinicopathological factors of age, histological grade and volume of ascites $(\mathrm{P}>0.05)$.

\section{Discussion}

To our knowledge, the present study is the first to conduct a FOXC1 immunohistochemical examination in serous ovarian tumors. In the study, endogenous expression of FOXC1 mRNA and protein was confirmed in two serous ovarian cystadenocarcinoma cell lines SKOV-3 and HO-8910 with RT-qPCR and western blot analysis. The subcellular location of FOXC1 protein was immunohistochemically detected in the two cell lines and in $57.5 \%$ (46/80 cases) of serous ovarian tumors.
FOXC1 protein was present in $84 \%$ of serous ovarian cystadenomas and $66.7 \%$ of borderline cystadenomas, whereas its expression was observed in only $37.5 \%$ of adenocarcinomas. Our retrospective study demonstrated that positive immunostaining for FOXC1 protein significantly decreased with advancing FIGO stage (I-II vs. III-IV) as well as pathological subtypes from benign to borderline and malignant tumors (Table I).

As demonstrated in the study, the differential FOXC1 staining in these three major categories of serous ovarian tumors may provide evidence for a different pathogenetic basis for benign, borderline and malignant serous ovarian tumors. The observation sparked our interest in the potential role of FOXC1 gene in ovarian tumorigenesis and the correlation between FOXC1 protein and clinicopathological characteristics. Notably, exclusively cytoplasmic immunostaining for FOXC1 protein was observed in serous ovarian tumor tissues and normal endometrial tissues used as positive controls, whereas both nuclear and cytoplasmic localization of FOXC1 protein was observed in the two cell lines, with expression levels in the nucleus markedly higher than those in the cytoplasm (Fig. 1C). This result was in discordance with previous studies reporting that the wild-type full-length FOXC1 protein was localized exclusively in the nucleus in almost all cells, due to two independent nuclear localization signals within FOXC1 FHD (27-29). FOXC1 has been identified as a phosphoprotein, and the activity of the transcriptional inhibitory domain located at amino acids 215-366 may be regulated by phosphorylation (30). In previous studies, FOXO1 (FKHRL1) protein, which is also a FOX family member, phosphorylated by AKT, was observed to be located in the cytoplasm, whereas unphosphorylated FOXO1 protein was observed in the nucleus and acted as a transcription factor for various genes, including, presumably, FAS ligand (tumor necrosis factor superfamily member 6) (31). However, it is unclear whether there are similar mechanisms of $\mathrm{FOXC1}$ protein in ovarian tumors. One plausible explanation for this phenomenon may be phosphorylation, which accounts for the protein shuttling between the nucleus and cytoplasm in the two cell lines and tumor tissues. FOXC1 expression in the cytoplasm may act as a tumor suppressor when unphosphorylated.

The present study has limitations. Phosphorylated FOXC1 antibody is no longer available commercially. Therefore it is now impossible for us to verify whether FOXC1 protein in the nucleus is phosphorylated or not. Fifteen out of 40 cases of serous ovarian cystadenocarcinoma (37.5\%) revealed FOXC1-positive expression, which was correlated with poorer histological grade and increased volume of ascites. However, no significant associations were observed between FOXC1 protein expression and clinicopathological factors including histological grades and volume of ascites. A possible explanation might be that the total number of malignant cases was not large enough to analyze clinical significance. For further studies, a larger number of malignant tumor cases should be recruited to better understand the trend between FOXC1 protein expression and the clinicopathological factors of histological grade and volume of ascites. In addition, the mechanism of subcellular mislocation of FOXC1 protein should be investigated to determine whether these interactions are regulated through phosphorylation. 
In conclusion, high expression of $\mathrm{FOXC1}$ protein may be correlated with a benign pathological subtype of serous ovarian tumors and a trend towards good prognosis. The molecular mechanism underlying FOXC1 protein in ovarian tumorigenesis remains to be explored.

\section{Acknowledgements}

The authors thank Professors Liping Zhang, Xiaoqiu Xiao and Xiaoni Zhong for their support, as well as Professors Youde Cao and Ying Ma for their expertise and assistance in the immunohistochemical analysis of serous ovarian tumors. The authors also acknowledge Mr. Zhengyi Wang in the Institute of Life Science of Chongqing Medical University.

Financial support was provided by the Natural Science Fund Programmes of Chongqing Science and Technology Committee and Scientific Research Projects of Chongqing Health Bureau (CSTC. 2006BB5279).

\section{References}

1. Parkin DM, Bray F, Ferlay J and Pisani P: Global cancer statistics, 2002. CA Cancer J Clin 55: 74-108, 2005.

2. Landis SH, Murray T, Bolden S and Wingo PA: Cancer statistics, 1999. CA Cancer J Clin 49: 8-31, 1999.

3. Wu A: Epidemiological analysis of gynecological malignant carcinoma. Bulletin of Chinese Cancer 6: 3-5, 1997 (In Chinese).

4. Weinberg RA: Tumor suppressor genes. Science 254: 1138-1146, 1991.

5. Mears AJ, Jordan T, Mirzayans F, Dubois S, Kume T, Parlee M, Ritch R, Koop B, Kuo WL, Collins C, et al: Mutations of the forkhead/winged-helix gene, FKHL7, in patients with Axenfeld-Rieger anomaly. Am J Hum Genet 63: 1316-1328, 1998.

6. Nishimura DY, Swiderski RE, Alward WL, Searby CC, Patil SR, Bennet SR, Kanis AB, Gastier JM, Stone EM and Sheffield VC: The forkhead transcription factor gene FKHL7 is responsible for glaucoma phenotypes which map to 6p25. Nat Genet 19: 140-147, 1998.

7. Lai E, Clark KL, Burley SK and Darnell JE Jr: Hepatocyte nuclear factor 3/fork head or 'winged helix' proteins: A family of transcription factors of diverse biologic function. Proc Natl Acad Sci USA 90: 10421-10423, 1993.

8. Xuan S, Baptista CA, Balas G, Tao W, Soares VC and Lai E: Winged helix transcription factor BF-1 is essential for the development of the cerebral hemispheres. Neuron 14: 1141-1152, 1995

9. Kume T, Jiang H, Topczewska JM and Hogan BL: The murine winged helix transcription factors, Foxc1 and Foxc2, are both required for cardiovascular development and somitogenesis. Genes Dev 15: 2470-2482, 2001.

10. Shu W, Yang H, Zhang L, Lu MM and Morrisey EE: Characterization of a new subfamily of winged-helix/forkhead (Fox) genes that are expressed in the lung and act as transcriptional repressors. J Biol Chem 276: 27488-27497, 2001.

11. Hatini V, Huh SO, Herzlinger D, Soares VC and Lai E: Essential role of stromal mesenchyme in kidney morphogenesis revealed by targeted disruption of Winged Helix transcription factor BF-2. Genes Dev 10: 1467-1478, 1996.

12. Lehmann OJ, Sowden JC, Carlsson P, Jordan $\mathrm{T}$ and Bhattacharya SS: Fox's in development and disease. Trends Genet 19: 339-344, 2003.

13. Ang SL and Rossant J: HNF-3 beta is essential for node and notochord formation in mouse development. Cell 78: 561-574, 1994.
14. Brody SL, Yan XH, Wuerffel MK, Song SK and Shapiro SD: Ciliogenesis and left-right axis defects in forkhead factor HFH-4-null mice. Am J Respir Cell Mol Biol 23: 45-51, 2000.

15. Pierrou S, Hellqvist M, Samuelsson L, Enerbäck S and Carlsson P: Cloning and characterization of seven human forkhead proteins: binding site specificity and DNA bending. Embo J 13: 5002-5012, 1994.

16. Gould DB, Mears AJ, Pearce WG and Walter MA: Autosomal dominant Axenfeld-Rieger anomaly maps to 6p25. Am J Hum Genet 61: 765-768, 1997.

17. Mirzayans F, Mears AJ, Guo SW, Pearce WG and Walter MA: Identification of the human chromosomal region containing the iridogoniodysgenesis anomaly locus by genomic-mismatch scanning. Am J Hum Genet 61: 111-119, 1997.

18. Kume T, Deng KY, Winfrey V, Gould DB, Walter MA and Hogan BL: The forkhead/winged helix gene Mf1 is disrupted in the pleiotropic mouse mutation congenital hydrocephalus. Cell 93: 985-996, 1998.

19. Winnier GE, Kume T, Deng K, Rogers R, Bundy J, Raines C, Walter MA, Hogan BL and Conway SJ: Roles for the winged helix transcription factors MF1 and MFH1 in cardiovascular development revealed by nonallelic noncomplementation of null alleles. Dev Biol 213: 418-431, 1999.

20. Carlsson P and Mahlapuu M: Forkhead transcription factors: Key players in development and metabolism. Dev Biol 250: 1-23, 2002.

21. Swiderski RE, Reiter RS, Nishimura DY, Alward WL, Kalenak JW, Searby CS, Stone EM, Sheffield VC and Lin JJ: Expression of the Mf1 gene in developing mouse hearts: Implication in the development of human congenital heart defects. Dev Dyn 216: 16-27, 1999.

22. Lehmann OJ, Ebenezer ND, Jordan T, Fox M, Ocaka L, Payne A, Leroy BP, Clark BJ, Hitchings RA, Povey S, et al: Chromosomal duplication involving the forkhead transcription factor gene FOXC1 causes iris hypoplasia and glaucoma. Am J Hum Genet 67: 1129-1135, 2000.

23. van der Heul-Nieuwenhuijsen L, Dits NF and Jenster G: Gene expression of forkhead transcription factors in the normal and diseased human prostate. Bju Int 103: 1574-1580, 2009.

24. Zhou Y, Kato H, Asanoma K, Kondo H, Arima T, Kato K, Matsuda T and Wake N: Identification of FOXC1 as a TGF-beta1 responsive gene and its involvement in negative regulation of cell growth. Genomics 80: 465-472, 2002.

25. Kaku T, Ogawa S, Kawano Y, Ohishi Y, Kobayashi H, Hirakawa T and Nakano H: Histological classification of ovarian cancer. Med Electron Microsc 36: 9-17, 2003.

26. Benedet JL, Bender H, Jones H III, Ngan HY and Pecorelli S: FIGO staging classifications and clinical practice guidelines in the management of gynecologic cancers. FIGO Committee on Gynecologic Oncology. Int J Gynaecol Obstet 70: 209-262, 2000.

27. Saleem RA, Banerjee-Basu S, Berry FB, Baxevanis AD and Walter MA: Analyses of the effects that disease-causing missense mutations have on the structure and function of the winged-helix protein FOXC1. Am J Hum Genet 68: 627-641, 2001.

28. Saleem RA, Banerjee-Basu S, Murphy TC, Baxevanis A and Walter MA: Essential structural and functional determinants within the forkhead domain of FOXC1. Nucleic Acids Res 32: 4182-4193, 2004.

29. Saleem RA, Banerjee-Basu S, Berry FB, Baxevanis AD and Walter MA: Structural and functional analyses of disease-causing missense mutations in the forkhead domain of FOXC1. Hum Mol Genet 12: 2993-3005, 2003.

30. Berry FB, Saleem RA and Walter MA: FOXC1 transcriptional regulation is mediated by $\mathrm{N}$ - and $\mathrm{C}$-terminal activation domains and contains a phosphorylated transcriptional inhibitory domain. J Biol Chem 277: 10292-10297, 2002.

31. Brunet A, Bonni A, Zigmond MJ, Lin MZ, Juo P, Hu LS, Anderson MJ, Arden KC, Blenis J and Greenberg ME: Akt promotes cell survival by phosphorylating and inhibiting a Forkhead transcription factor. Cell 96: 857-868, 1999. 